\title{
Transitory Income Shocks and Essential Household Consumption Expenditures in Rural Kenya
}

\author{
Philip K Musyoka $^{1^{*}} \quad$ Joseph Onjala $^{2} \quad$ Leopold P. Mureithi ${ }^{1}$ \\ 1.School of Economics, University of Nairobi, Kenya \\ 2.Institute of Development Studies, University of Nairobi, Kenya
}

\begin{abstract}
Majority of rural households in developing economies derive their livelihoods from agriculture, a sector that is highly prone to transitory shocks. In the absence of effective coping mechanisms, these households are unable to smoothen consumption and are thus likely to experience fluctuations in consumption expenditures. This study examines the effect of transitory income shocks on different categories of household expenditures, focusing on spending on essential goods and services such as food, health and education in rural Kenya. The study explores the heterogeneity in households and consumption to test the permanent income hypothesis using a sample of 5,828 rural households disaggregated along two distinct agro-ecological zones. Decomposing household income into permanent and transitory components failed to yield distinct estimates of permanent and transitory incomes when applied to this study's data. We therefore modified the estimation approach to capture the effect of transitory income shocks by introducing a dummy of crop loss in the household expenditure equation. Our results show that in the countrywide sample, households that experienced crop loss had a statistically significant reduction in the aggregate, food and non-food expenditures compared to the ones that did not. For the high and medium potential agro-ecological zones sample, we found that consumption expenditures were not associated with crop loss. In the arid and semi-arid zones sample, aggregate and food expenditures reduced for households affected by crop loss. The findings provide a basis of policy recommendations on the need for the existing government poverty alleviation programmes to focus on drivers of impoverishment such as transitory income shocks.
\end{abstract}

Keywords: transitory income shocks, consumption expenditure, agro-ecological zones, Kenya

DOI: $10.7176 / \mathrm{JESD} / 10-12-04$

Publication date:June $30^{\text {th }} 2019$

\section{Introduction}

Majority of rural households in developing economies derive their livelihoods from agriculture, a sector that is highly prone to transitory shocks. In the absence of effective coping mechanisms, these households are unable to smooth consumption and are thus likely to experience fluctuations in consumption expenditures which in the extreme cases can plunge households into poverty (Townsend, 1994; Udry, 1995; Günther and Harttgen, 2009). In the advanced economies with efficient risk sharing systems, household consumption has been found to be insensitive to transitory income shocks (Blundell, Pistaferri and Preston, 2008). Nonetheless, households prefer smooth consumption and have been shown to institute measures to safeguard consumption from income fluctuations. Governments and non-government institutions also implement social safety nets and programmes to shield vulnerable households from consumption fluctuations.

Agriculture in developing countries is still prone to the risk of weather, production (pests, storage) and economic (price/market) shocks. The magnitude of losses due to these shocks is reflected in a FAO (2017) report that estimated that shocks-prone developing countries lost approximately USD 93 billion in livestock and crops from natural-climatic related shocks between 2005 and 2014. Consequently, these risks and shocks are transmitted to farming households as manifested in welfare indicators such as hunger, malnutrition, depressed consumption and poverty (Webb, et al. 2018). One possible transmission mechanism is through the numerous transitory income shocks characteristic in subsistence agriculture in sub-Saharan Africa (McCarthy, Brubaker and De La Fuente, 2016). Because transitory income shocks are short-lived, they are less likely to attract attention of government and other relevant stakeholders. In addition, if the shocks are severe and recurrent - often in different forms and types -, their camouflaged effects can destabilize household incomes with potential adverse effects on household welfare.

At the aggregate level, the performance of key household welfare indicators such as food and nutrition, health and education tracks the GDP performance in Kenya (Republic of Kenya, various years). At the household level, households depended on agriculture are most likely to fund their expenditures from agricultural proceeds such as sale of crops, animals and wages in derived from providing labour to agricultural-based enterprises. When incomes from these sources fluctuate due to shocks, household expenditures may fluctuate accordingly or remain stable owing to internal and external household interventions put in place to ensure smooth consumption. This study investigates what happens to households' expenditures on essential consumption of food and nutrition, health and education when household agricultural income fluctuates due to transitory shocks. The findings have relevant policy implications on rural poverty, specifically on highlighting the challenges of income variability on essential consumption expenditures for rural households in Kenya. Specific policies to stabilize rural agricultural 
household's income from fluctuations as well as to shield essential consumptions from income fluctuations can then be developed to contribute to rural poverty reduction. The study explores the heterogeneity in households and consumption. For instance, the disaggregation of consumption expenditures compares and contrasts the extent of vulnerability to transitory income shocks of essential consumption expenditures. A related study, Wineman, et al., (2016) disaggregated households according to geographical zones to estimate the welfare effects of weather shocks for rural households in Kenya. However, Wineman, et al., (2016) limits welfare measurement to household income receipts and does not consider consumption expenditures, which is the focus of the current study.

\section{The Context of Shocks and Household Welfare in Kenya}

The relationship in shocks and household welfare in developing countries has attracted considerable academic investigations (see for example Hoddinott, 2006; Günther and Harttgen, 2009; Kim and Prskawetz, 2010; Baez, et al., 2017). Using a nationally representative cross-sectional data for rural areas, this study contributes to the existing literature by examining the effect of transitory income shocks on different categories of household expenditures, but focusing on spending on essential goods and services such as food, health and education. The association of household consumption expenditures with vulnerability to transitory income shocks is analyzed along the agro-ecological disaggregation in the recognition that zones differ in climatic conditions, land forms and soil type. These characteristics influence the vulnerability of rural households to various shocks such as drought, flooding and crop pests and disease that contribute to crop loss - which subsequently results to fluctuations in household transitory incomes. By disaggregating the sample size along climatic zones and focusing on different categories of expenditure, this study explores the sensitivity of household spending to transitory income shocks as well as the extent to which households insulate the essential expenditures from shocks.

About 70 percent of the 74 percent of Kenya's rural population is employed in agriculture and thus depends on income mainly from crop and livestock production as well as farm-based wages (World Bank, 2018; Food and Agriculture Organization of the United Nations (FAO), 2018). This population is prone to livelihood fluctuations caused mainly by negative shocks that perennially affect the agriculture sector in the country. Common shocks include recurring droughts that depress domestic food production, slacken performance of the manufacturing and services industry, and increase conflict over natural resources (Mbogo, Inganga and Maina, 2015); floods, forest fires and landslides (Obiero and Onyando, 2013; Opere, 2013; Parry et al., 2012); pests and crop and livestock diseases (Pritchett, Thilmany and Johnson, 2005; Rich and Wanyoike, 2010) and economic shocks such as input and output price fluctuations. Agriculture-dependent households also face structural challenges such as inaccessible markets, financing constraints and outdated agricultural production technologies that cumulatively contributes to low and unstable incomes (Salami, Kamara and Brixiova, 2010). Consequently, agriculturedependent households have lower per-capita incomes and experience more monthly income fluctuations than nonagriculture dependent rural households (Collins, Cojocaru and Zollman, 2015). Indeed, among the rural households, the median standard deviation of monthly per-capita income was higher for agriculture-dependent households by 38 percentage points (ibid). 


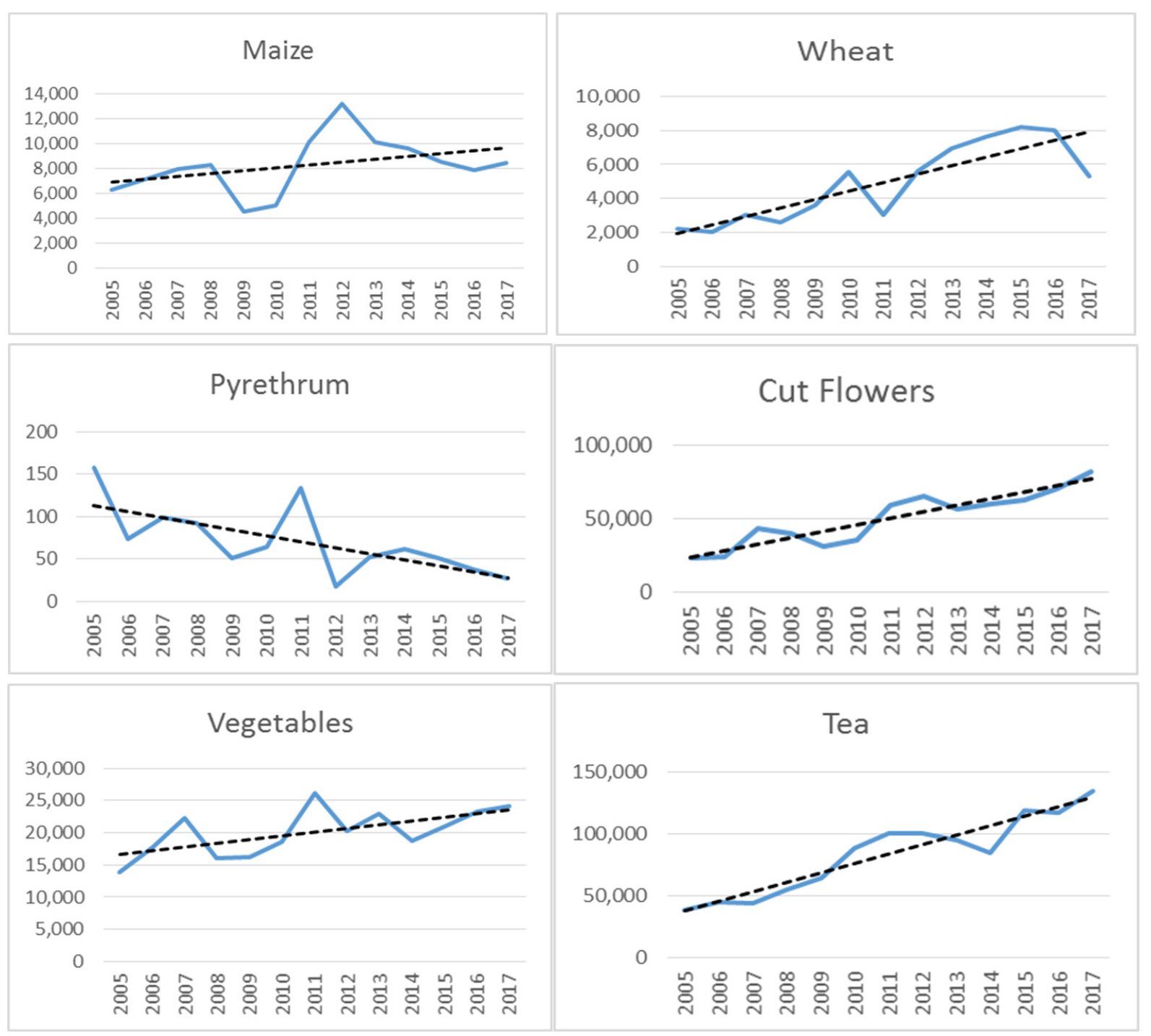

Figure 1: Marketed production of various crops produced in Kenya at current prices (KES)

The occurrence of frequent and unanticipated shocks in household agricultural production reflects the observed annual fluctuations in aggregate output of key food crops in Kenya. Figure one shows that agricultural output - as measured in monetary value - of maize, wheat, cut flowers, vegetables, pyrethrum and tea. The figures show that the output of the crops produced by mainly the smallholder farmers fluctuates most (see for example maize and vegetables, compared with cut flowers and tea which are produced by established firms in controlled environments and have established value chains for marketing). In addition, an analysis of marketed crop and animal produce (see table seven and eight in the appendix) by households disaggregated by the counties demonstrates that income from agriculture largely reflects the country's agro-ecological zones. Households in counties in high agricultural-potential zones such as Bomet, Meru, Uasin Gishu and Nyandarua earned more than the households in arid counties (such as Mandera, Marsabit, Turkana, Garissa, Samburu and Wajir) by a factor of 300. On the other hand, counties in the arid and semi-arid lands (ASALs) with zero or negligible earnings from sale of crops reported mean animal sales of above KES. 10,000 in livestock sales. This direct relationship between households' crop and livestock earnings implies that rural livelihoods are still beholden to their surrounding natural environments.

\section{Literature}

Income and consumption are important indicators of welfare and their both short and long term relationship has been explored comprehensively in theoretical and empirical literature. Pioneering the theory of this relationship include Modigliani and Brumberg (1954) who postulated that household decision making regarding consumption followed needs of different ages and constrained by their income. This postulate led to the lifecycle theory of consumption. Related to the lifecycle consumption hypothesis is the permanent income hypothesis, developed by Friedman (1957), that premise that household's consumption decision at specific point in time is dependent on the 
expected lifetime income and not the income at the point of the specified consumption.

The general upshot of these theories collectively referred to as lifecycle-permanent income hypothesis (PIH) is that transitory income changes does not affect consumption; rather consumption is affected by changes in permanent income. These theories are augmented by considerations of precautionary savings motive that explains how economic agents use savings to smooth consumption over time (Weil, 1993; Carroll, 2001). In addition to $\mathrm{PIH}$, the theory of complete market hypothesis $(\mathrm{CMH})$ has been proposed to explain how economic agents can share risks through insurance and credit markets thus realizing stable consumption in the face of income variations, but on condition that these markets worked efficiently (Cochrane, 1991; Mace, 1991; Townsend, 1994; McCarthy, 1995). In reality, full insurance is not perfect as exemplified by Cochrane (1991) to the extent that households are only able to insure against consumption fluctuations caused by idiosyncratic income shocks, but not when shocks are covariate. In the case that households face liquidity constraints or are unable to insure consumption against income shocks, the lifecycle-permanent income hypothesis is empirically rejected (Zeldes, 1989), implying that consumption tracks the income process irrespective of whether the change in income was anticipated or otherwise. To seek yet more theoretical grounding of household behavior in the face of income shocks in low resource countries, Zimmerman and Carter (2003) developed the asset smoothing theory (AST) whose central tenet is that households can either smooth consumption or assets depending on asset levels.

In ideal situations, households have access to working markets for insurance, credit and other financial instruments to smooth consumption. In most of the developing economies, these markets are largely non-perfect thus exposing consumption to variations. In situations of imperfect markets for credit and insurance for example, some households save and dissave as a strategy to smooth consumption profiles in the face of transitory income shocks (Deaton, 1989). The theory of saving differs from the asset smoothing theory in that assets are accumulated and liquidated in the short term with the aim of smoothing consumption, effectively leaving households with relatively small assets holdings, while in asset smoothing theory, the focus is to maintain stable asset levels at the risk of consumption fluctuations (Deaton, 1989; Zimmerman and Carter, 2003). The complete market hypothesis is argued to work among communities in developing countries due to the practice of community-driven informal insurance system that is supported by geographical proximity of households and socio-cultural and ethnographic homogeneity that reduces challenges of information asymmetry and enforcement of contracts (Morduch, 2004).

The link between income fluctuations and household consumption in developing countries has generated substantial academic and policy interest. Households in developing economies face more widespread and persistent income shocks owing to the fact that their livelihoods are mainly depended on nature (Dercon, 2002; Baez, Kronick and Mason, 2013) and limited infrastructure as well as the spatially-covariant risk and the problems of adverse selection and moral hazard that cumulatively limit the working of formal risk sharing, insurance and credit markets (Rosenzweig, 2001). This has brought forth literature such as the informal systems of risk sharing that is based on drawing upon household and society-wide resources such as social networks (Morduch, 1999; Kumar and Singh, 2012). The argument in this theory is that an efficient communal risk sharing should protect individual household consumption from individual income risks (Morduch, 1999). Since the informal risk sharing mechanisms are weak and inadequate, governments and donors theoretically play the role of redistributing incomes, safeguarding household assets and protecting household consumption from fluctuations through various types of safety net programmes (Subbarao, et al., 1997; Alderman and Haque, 2006).

The empirical testing of the permanent income hypothesis of consumption smoothing in developing countries include the pioneering works by Wolpin (1982) who found that rural households in India attempted to smooth consumption from income shocks caused by weather variability. Other related early empirical studies include Deaton (1990) and Townsend (1994) who found that household consumption was only marginally affected by household income among villagers in rural Côte d'Ivoire and India respectively. However, both studies rejected the hypothesis of full insurance. However, Nguyen, White and Ma (2018) did not find empirical evidence in support of PIH among poor rural households in Vietnam, unlike the CMH and AST which were empirically vouched using the same data sample.

The empirical testing of permanent income hypothesis has also widened scope to incorporate various dimensions in consumption smoothing, specifically how households in low-income environments achieve nonvarying consumption process. For instance, Rosenzweig and Wolpin (1993) and recently Berloffa and Modena (2013) have examined the role of asset endowment in household consumption response to income shocks in rural India and Indonesia respectively. The other commonly studied means of consumption smoothing is the use of communal risk-sharing through informal insurance mechanisms (Udry, 1990; Grimard, 1997; Fafchamps and Lund, 2003). The nature of shocks also determine how household consumption respond, with Kim, et al. (2009) finding that a birth in a sample of Indonesian rural households reduced individual consumption in the family. Related literature in the East African context has found rural households' consumption to be generally vulnerable to livelihood shocks (Christiaensen and Subbarao, 2004; Asiimwe and Mpuga, 2007) while the AST was empirically found to hold in pastoral households in northern Kenya (see McPeak, 2004).

There is consensus from the review of literature that households strive to smooth consumption when hit by 
shocks. However, the extent of this consumption smoothing is influenced by a myriad of factors and circumstances as documented in the literature. In the existing literature on this subject, consumption is mostly lumped together. The contribution of this study is to assess the effect of transitory income shocks on components of household consumption, specifically the effect on essential consumption such as food, health and education.

\section{Methodology and Estimation Approach}

As highlighted in the review of literature, household consumption is theoretically expected to be immune from transitory income shocks. However, the mechanisms for smoothing consumption in less developed countries are imperfect thus rendering the effect of transitory income shocks on household consumption a matter of empirical investigation. Concretely, markets for formal credit and insurance markets are limited, especially in rural areas. The alternative risk sharing arrangements characterized by informal networks have been empirically found not to provide full insurance (Udry, 1990; Grimard, 1997; Fafchamps and Lund, 2003). In the absence of functioning financial markets and efficient risk-sharing mechanisms, other options available to households include accumulation and liquidation of assets (Paxson, 1992; Rosenzweig and Wolpin, 1993), selling of labour (Kochar, 1999) and relying on emergency transfers (Maxwell, et al., 2010). Without proper risk managements, shocks lead to consumption volatility at the household level.

Conceptually, the effect of income shocks on consumption expenditure as adapted from Jappelli and Pistaferri (2010) indicates a distinction between permanent and transitory nature of shocks. However, irrespective of persistence of the shocks, they contribute to unanticipated income change which may or may not be manifested through a consumption response. This roadmap is presented diagrammatically in figure two. For the sampled households in this study, crop and animal losses are mostly contributed by weather variations - which are usually unanticipated.

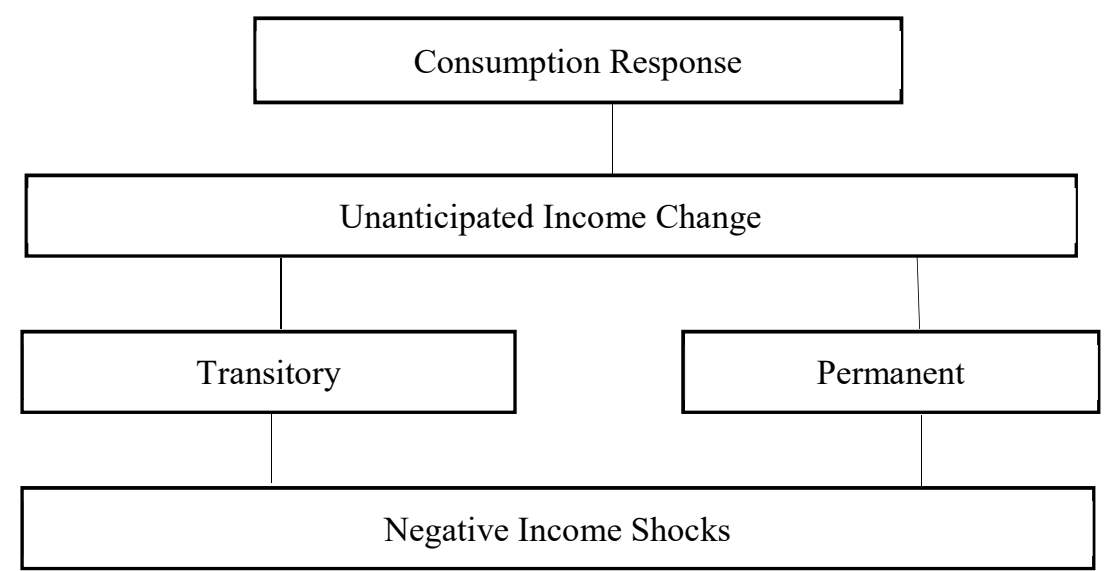

Figure 2: Conceptual Framework - Characterizing consumption response from income shocks Source: Adapted from Jappelli and Pistaferri (2010)

Having conceptually formulated the paths through which household expenditure is influenced by income variability, this study follows the standard approach in consumption-smoothing literature of first decomposing household income into its permanent and transitory components in order to empirically assess the effect of transitory income shocks on household consumption expenditures using a rural-based sample (Paxson, 1992; Jacoby and Skoufias, 1997; Fafchamps, Udry and Czukas, 1998; Cameron and Worswick, 2001; Kazianga and Udry, 2006; Sirisankanan, 2015). In this estimation approach, since income is conceived to consist of both the permanent $\left(Y^{P}\right)$ and transitory $\left(Y^{T}\right)$ components, the first step in the estimation is to separate permanent and transitory components of income. Therefore, as shown in equation one of household income $\left(Y_{i}\right)$, there is a vector of variables that are assumed to affect the permanent component of household income $\left(X_{i}^{P}\right)$ as well as different vector of variables that determine the transitory income component $\left(X_{i}^{T}\right) \cdot \alpha_{0}, \alpha_{1}$ and $\alpha_{2}$ are parameters and $\epsilon_{i}$ is a mean zero error term. The error term is assumed to be independently and identically distributed (i.i.d).

$Y_{i}=\alpha_{0}+\alpha_{1} X_{i}^{P}+\alpha_{2} X_{i}^{T}+\epsilon_{i}$

The computation of equation one produces estimates of permanent income, $Y^{P}$, and transitory income $Y^{T}$ and $\epsilon_{i}$, indicated by equations two, three and four as follows;

$$
\begin{aligned}
& \hat{Y}_{i}^{P}=\hat{\alpha}_{0}+\hat{\alpha}_{1} X_{i}^{P} \\
& \hat{Y}_{i}^{T}=\hat{\alpha}_{2} X_{i}^{T} \\
& \widehat{\epsilon}_{\imath}=\hat{\alpha}_{0}-\hat{\alpha}_{1} X_{i}^{P}-\hat{\alpha}_{2} X_{i}^{T}
\end{aligned}
$$

As per the authors, the second step is to assess the impact of transitory income shocks on household consumption expenditure, shown by equation five. The objective of this study is to estimate the effect of transitory income shocks on different components of household consumption expenditures. Thus, consumption expenditure, 
$\left(E X P_{i}\right)$ will take different forms such as aggregate household spending as well as food, non-food, education and health expenditures.

$$
E X P_{i}=\eta_{0}+\eta_{1} \hat{Y}_{i}^{P}+\eta_{2} \hat{Y}_{i}^{T}+\eta_{3} \hat{\epsilon}_{i}+\eta_{4} X_{i}+\mu_{i}
$$

In equation five, $\hat{Y}_{i}^{P}, \hat{Y}_{i}^{T}$ are the estimated values of permanent and transitory components of household incomes, while $\hat{\epsilon}_{i}$ represents the residuals of the income equation (equation one). $X_{i}$ is a vector of variables that are expected to affect household expenditure such as size and age structure of the household, while $\eta_{0}, \eta_{1}, \eta_{2}, \eta_{3}$ and $\eta_{4}$ are estimation parameters and $\mu_{i}$ is mean zero error term. Meghir (2004) found that the propensity to consume is affected by household demographic characteristics such as the number and age composition of the household members, which dictate the consumption needs and preferences over time.

In line with the permanent income hypothesis of perfect consumption smoothing, it is expected that the marginal propensity to consume (MPC) out of permanent income $\left(\eta_{1}\right)$ should be near one while the MPC out of transitory income $\left(\eta_{2}\right)$ is expected to be zero because all transitory income is saved (or dissaved). A coefficient on transitory income that is significantly greater than zero indicates a case of households that are unable to smooth consumption. Cameron and Worswick (2001) further contend that the coefficient on the residual term $\hat{\epsilon}_{i}$ will lie between zero and one since the variable contains unobserved components of both permanent and transitory income.

We introduce the disaggregation of the sample size based on agro-ecological zones because the transitory income shocks are due to weather-related occurrences such as drought and floods as well as geographicallyisolated incidences such as crop and animal diseases and water shortages. This disaggregation therefore helps to isolate the degree of household ability to insulate consumption from income shocks, which by extension demonstrates the state of formal infrastructure of risk sharing (presence of banks, insurance); various strength of social networks. The disaggregation also demonstrates the household vulnerability to shocks along climatic zones, persistence of transitory shocks due to recurring droughts (that depletes household buffer stocks).

Kenya is formally divided into six agro-ecological zones, agro-alpine, high potential, medium potential, semiarid, arid and very arid (Republic of Kenya, 2012). In this study, we categorize the zones into two; high and medium potential zones (referred in this study as highlands) and arid and semi-arid lands (ASALs). The agroalpine mainly at the vicinity of mountains and are excluded in this study since they are not used for agricultural production and are mostly uninhabited. The sampling framework used in collection of the data for this study weighted the population density and for that reason, the final sample size used in this analysis reflects the population density of the two agro-ecological zones. While the ASALs constitute more than 80 percent of the country's land mass, only about a third of the population reside there (Republic of Kenya, 2017).

On the other hand, disaggregation of consumption expenditures makes it easier to isolate specific changes to household consumption expenditures due to transitory income shocks. In addition, the disaggregation helps unmask whether consumption responses to income shocks indicate varying priorities for essential household expenditures analyzed, that is food, education and health. Cumulatively, all these disaggregation aids the exploration of heterogeneity of livelihoods and vulnerability in Kenyan households.

Table 1: Disaggregation of respondents per agro-ecological zones

\begin{tabular}{ll}
\hline Agro-ecological zone & Sample size \\
\hline High and medium potential areas & 4,203 \\
Arid and Semi-arid & 1,625 \\
Number of observations & 5,828 \\
\hline
\end{tabular}

In this study, shocks are household accounts of various events that negatively affected welfare in the period of five years prior to data collection. Self-reported shocks are potentially biased, especially for long recall periods and varying subjectivity in determining the severity of shocks. To avoid recall bias, preventive measures were undertaken during collection of the data used for this study. In addition, since households were allowed to report multiple shocks, where more than one shock contributed to crop loss per household, the study adopted the most recent one - in order to minimize recall bias and also to synchronize crop loss and household consumption expenditures. Further still, the self-reported instances of crop loss in the different survey areas at the different times was compared with the information from external sources (see for instance https://reliefweb.int/report/kenya/kenya-food-security-update-february-2006) and there was convergence. Subjectivity in household assessment of the severity of shocks causing crop loss was also found not to be a serious bias after 65 percent of the clusters ${ }^{1}$ showed convergence of households' assessment of the severity or non-severity of the shocks. In addition, crop loss is a covariate shock with the likelihood of affecting many households in its wake.

The occupation of household head is categorized as those in waged employment-indicating those with secure and stable sources of income; small business employment - indicating the occasional workers in stable industries, casuals in service industry and others with semi-secure sources of income; and agricultural employment-

\footnotetext{
${ }^{1}$ Cluster is the enumeration area, consisting of 10 households drawn from the same village. Therefore, households within a cluster are expected to be likely homogeneous and face similar agro-climatic conditions.
} 
representing those in primary production such as farmers, livestock keepers and fisher-folks and thus characterized by insecure and fluctuating incomes. Except for the retired household heads receiving regular pension or other sources of regular income, the occupation of the retirees was classified as insecure, because of reduced earnings due to departure from active employment. Household heads with missing information on employment but were seeking work were coded as having insecure incomes.

The total household income is computed by adding income from crop and livestock sales, labour income, investment incomes and transfers is consistent with other studies (see for instance Krueger and Perri, 2006, p. 4; Sirisankanan, 2015, p. 6). The estimated coefficients of this study should be interpreted in consideration that the income variable used in the estimation model was found to be underreported, and could be subject to other limitations identified in the literature such as aggregation from disparate sources which fluctuate significantly due to seasons, especially for a data collected from rural households depended on rain-fed agriculture (Srivastava and Mohanty, 2010).

Income and consumption expenditures are used in regionally deflated prices in order to take care of spatial price variation that is evidently present in Kenya because of undeveloped transport networks especially in the arid and semi-arid regions (Deaton, 2003). Total expenditure is the aggregation of all consumption related expenditures reported by the households and includes food and non-food expenditures.

\subsection{Data}

The study uses the 2005/2006 Kenya Integrated Household Budget Survey (KIHBS), conducted in 1,343 randomly selected clusters, comprising 861 rural and 482 urban clusters. A random sample of 10 households was selected from each cluster, giving a sample size of 13,430 . The KIHBS is nationally representative and covers a wide range of household welfare topics such as education, health, agricultural production, shocks and expenditures. The study focused on respondents living in rural areas $(8,487$ households) because the crop-loss and animal loss shocks are most likely to affect more severely the farming households. However, 11 percent and 22 percent of households based in urban centres too reported being adversely affected by shocks that cause crop and animal losses respectively, but were not nevertheless used in the study. This can however, be attributable to a noted dualism in household livelihoods in developing countries in which urban based households run parallel income generating activities in the rural areas such as growing crops and keeping livestock. For the eventual analysis, the rural sample size was reduced to only 5,828 households after excluding outliers and observations with missing values. Households provided detailed information in modules covering family gender, age and educational attainment, shocks within the past five years, sources of income, consumption expenditures and agricultural holdings and activities. While the household-specific data was obtained from the KIHBS, rainfall and agro-ecological zoning data came from various publicly-available published reports.

\section{Results and Discussion}

In this section, the results of various estimations are presented and discussed, first the summary statistics, secondly the income equation estimates and finally the consumption expenditure estimates.

Table two provides a description of the variables used together with each variable's mean, standard deviation, as well as minimum and maximum values. Of the 5,828 households surveyed, 42 percent reported being affected by shocks that lead to crop loss, which are droughts and floods, crop diseases and pests. The proportion of households that experienced crop-loss related shocks, only 13 percent used labour strategies as a coping mechanisms. These labour-based coping mechanisms include working more and longer hours, other household members previously not working taking up work, starting up of new businesses, removing children from school to take up paid employment and migrating elsewhere to look for work. The low percentage of households that took up this coping option could indicate that there are limited farm and off-farm labour opportunities in Kenya's rural areas.

The mean value of total land owned by a household was KES. 96,600. However, the individual household observations were widely dispersed from this mean value as evidenced by the standard deviation of KES. 251,200. This could be due to the households that reported their land value to be zero while others reported their land worth KES. 4,500,000. Households that reported zero value for their landholdings constitute 49 percent of the sample size, a significant percentage that could indicate that the value was incorrectly measured or these households are using borrowed/leased land for crop production. Households who were affected by shocks had cheaper land at KES. 35,300 compared to the total population. This finding is consistent with the fact that crop loss shocks are more frequent in lower potential areas where value of land is generally cheaper than in high potential zones. 
Table 2: Summary Statistics

\begin{tabular}{lllll}
\hline Variable & Mean & Std. Dev. & Min & Max \\
Crop loss & .42 & .49 & 0 & 1
\end{tabular}

Variable Description

Dummy, 1 = household experienced crop loss, $0=$ otherwise

\begin{tabular}{lllll}
\hline $\begin{array}{l}\text { Labour supply } \\
\text { response }\end{array}$ & .13 & .33 & 0 & 1 \\
$\begin{array}{l}\text { Land value (KES) } \\
\text { (K),579.01 }\end{array}$ & $251,228.5$ & 0 & $4,500,000$
\end{tabular}

Dummy, $1=$ yes, $0=$ otherwise

Continuous, price the piece of land would fetch if it were to be sold

Crop loss $\times$ land value $\quad 35,276.37 \quad 149,952.5 \quad 0 \quad 3,800,000$

Interaction of land value and (KES) whether household experienced crop loss in KES

Number of household members between ages:

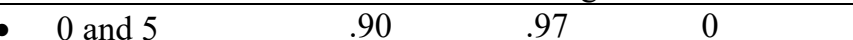

$1.11 \quad 1.11$

1.11

- 12 and 17

$.95 \quad 1.04$

- $\quad 18$ and 64

$2.44 \quad 1.41$

1.41

.22

.48

0

$0 \quad 7$

Continuous

- Over 65

No of household members over age 18 by education and gender:

0

7

7

Continuous

7 Continuous

\section{- Primary schooling (males)}

- Primary schooling (females)

- Secondary schooling (males)

- Secondary schooling (females)

- $\quad$ Post-secondary $\quad .08$ schooling (males)

- Post-secondary schooling (females)

Mean annual rainfall (millimetres)

Total income (KES)

.56

0

.54

0

$.41 \quad 0$

Continuous

12

Continuous

4

Continuous

Continuous

.15

.10

.33

0

3

3

3 Continuous

.28

.04

$.21 \quad 0$

$\begin{array}{llll}1,226.86 & 456.20 & 186 & 2,62 \\ 36,706.29 & 42,752.49 & 17.74\end{array}$

Total expenditure

(KES)

Food expenditure

(KES)

Nonfood and

$92,595.75$

$67,038.59 \quad 1,162.86$

$60,149.47 \quad 39,504.5 \quad 0$

$1,081,912$

Continuous

nondurable

expenditure (KES)

Education expenditure

\section{(KES)}

Health expenditure

$32,446.28 \quad 42,010.62 \quad 0$

$1,007,951$

Continuous

(KES)

Number of

observations

$\begin{array}{ccccc}6,875.00 & 19,529.45 & 0 & 616,100 & \text { Continuous } \\ 851.35 & 2,482.36 & 0 & 87,000 & \text { Continuous } \\ & & & 5,828 & \end{array}$

The mean annual income of the respondent was KES. 36,700 and a relatively wide deviation of KES. 42,800. As indicated elsewhere in this paper, we submit that households underreported on their earned incomes, and this could be the explanation of low annual incomes of KES. 18. The mean total household consumption was KES. 92,600 , which is higher than the reported incomes. The mean expenditure on food was KES. 60,100, also higher than the mean earned income. The zero values reported by households for food and non-food (food=2, nonfood $=25$ ) could indicate that these households depend solely on donated food supplies, which is plausible because the data indicates that these two households consist of one and two members. The mean education and health 
expenditures are relatively low at KES. 6,900 and KES. 850 respectively. Unlike the few observations in food and non-food expenditures with zero expenditures, households with zero education and health spending consist of 26 percent and 31 percent respectively. Zero spending on education can be explained by lifecycle of the households in addition to other possible reasons for zero spending on both education and health in rural areas such as unavailability of private educational and health facilities as well as reliance on self-medication.

The exploratory data analysis indicated that a wide dispersion of the household income. For instance, seven percent of the households reported zero income. These variations are likely to affect the estimation of the coefficients, and therefore the distribution was normalized by omitting seven percent of the reported lowest and highest incomes.

\subsection{Income Estimation Equation}

The results of the income estimation equation is provided in table three for the country and disaggregated according to the two classifications of the country's agro-ecological zones. The country's agro-ecological zones were classified into the high and the medium potential on one side, and on the other side is arid and semi-arid areas (ASALs). The estimation of the income equation (equation 1) was used to decompose household income into transitory and permanent components.

Table 3: Income Equation Estimates

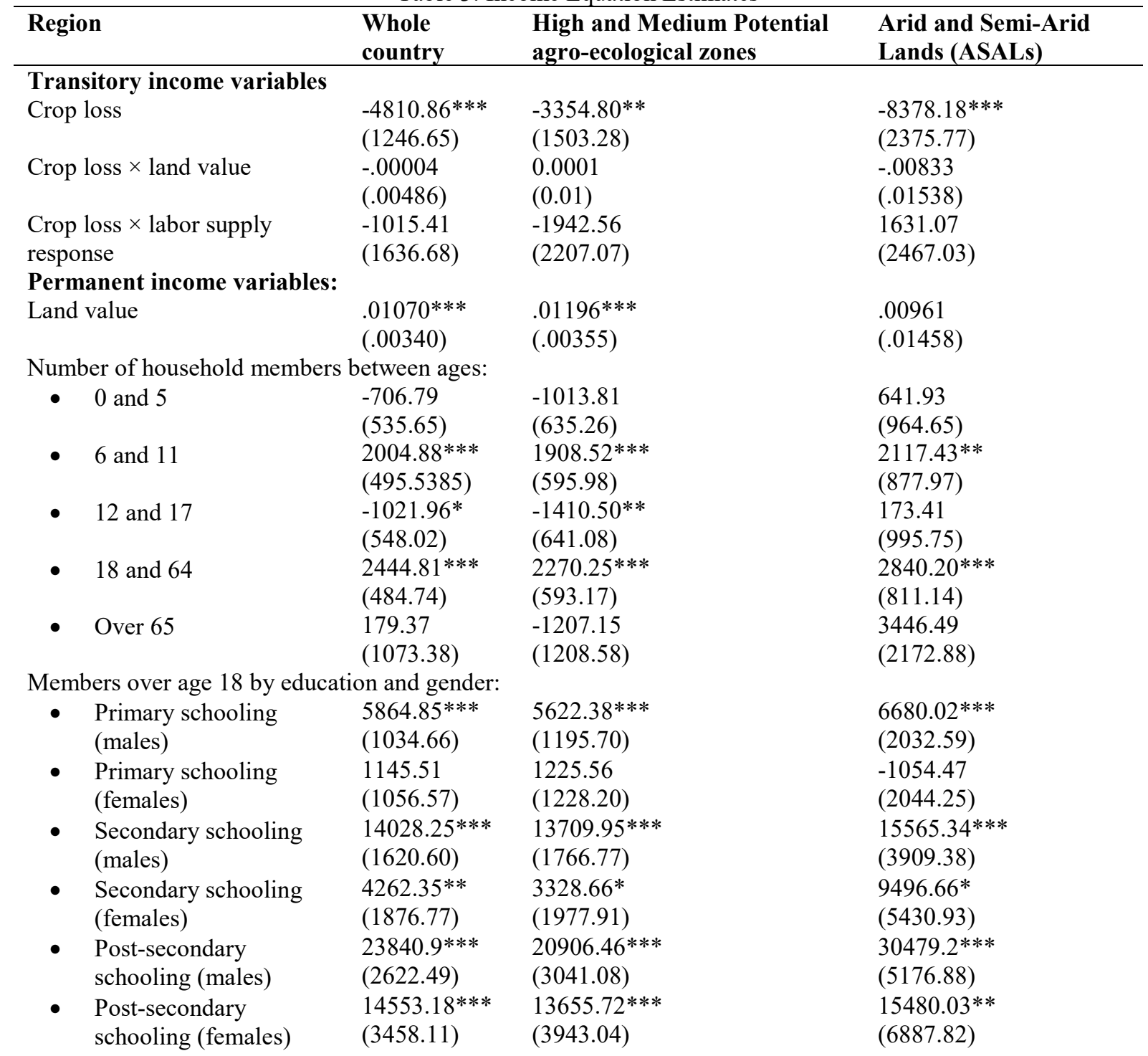




\begin{tabular}{|c|c|c|c|}
\hline Region & $\begin{array}{l}\text { Whole } \\
\text { country }\end{array}$ & $\begin{array}{l}\text { High and Medium Potential } \\
\text { agro-ecological zones }\end{array}$ & $\begin{array}{l}\text { Arid and Semi-Arid } \\
\text { Lands (ASALs) }\end{array}$ \\
\hline \multicolumn{4}{|c|}{ Household head occupation ('Waged' is reference category) } \\
\hline \multirow[t]{2}{*}{ - Small business } & $-16671.37 * * *$ & $-16554.82 * * *$ & $-17614.06 * * *$ \\
\hline & $(2509.65)$ & $(3013.85)$ & $(4417.81)$ \\
\hline \multirow{2}{*}{ - Agriculture } & $-35253.62 * * *$ & $-37237.07 * * *$ & $-31826.08 * * *$ \\
\hline & $(2183.88)$ & $(2614.29)$ & $(3929.79)$ \\
\hline \multirow[t]{2}{*}{ Mean annual rainfall } & $16.90 * * *$ & $-52.23 * * *$ & $50.82 * * *$ \\
\hline & $(4.26)$ & $(8.56)$ & $(12.63)$ \\
\hline \multirow[t]{2}{*}{ Square of mean annual rainfall } & $-.00875 * * *$ & $.01225 * * *$ & $-.02480 * * *$ \\
\hline & $(.00159)$ & $(.00260)$ & $(.00934)$ \\
\hline \multirow[t]{2}{*}{ Constant } & $46884.07 * * *$ & $103435 * * *$ & $25480.26 * * *$ \\
\hline & $(3769.97)$ & $(7455.16)$ & $(6261.05)$ \\
\hline No of observations & 5,828 & 4,203 & 1,625 \\
\hline R-squared & 0.2117 & 0.2248 & 0.2277 \\
\hline F-tests & $55.46 * * *$ & $42.70 * * *$ & $21.85 * * *$ \\
\hline
\end{tabular}

Robust standard errors are in brackets. $* * *, * *, *$ : significant at $1 \%, 5 \%$ and $10 \%$ respectively

Crop loss, which is a dummy indicating one if the household reported shocks likely to contribute to crop loss (such as drought, pests and diseases) and zero otherwise was found to negatively related to income and is statistically significant at one percent level for the whole country and ASALs samples, and at five percent for the households in the high and medium potential zones. Coefficients of the other determinants of transitory income in the model, that is, the interaction terms of crop loss with land value on one hand, and with a dummy for whether household responded through increasing labour-participation options, were found not to be statistically significant in all three equations. Crop loss dummy was interacted with land value because of the additive/multiplicative effect the shocks with the size of land under crop. It is expected that increased labour participation at the household will generate income to counteract the loss effect from crop loss shocks. This interactive effect was found to be absent in the three estimation models.

The variables for the estimation of permanent income component include land value which was found to have positive effect and statistically significant at one percent level in the models for the country-general and high potential zones. It is possible that land wealth for ASALs' households is marginalized and of limited economic value, thus the insignificance in explaining permanent income. The composition of household size was found to have positive effect across the three models for the 6-11 and 18-64 age cohorts. The size in these two age categories was found to have positive effect on the permanent component of the household income. For households in high potential zones, permanent income fell with the size of members in the 12-17 age cohort, while it was found not to influence income for their ASALs counterparts. However, the size of youngest (0-5 years) and the oldest (over 65 years) household members was found not to influence the size of permanent component of income.

In all the three models, the effect of education status of household adult members disaggregated by gender was found to be positive in all the education levels except for the size of females with primary school certificate. The coefficients of the positive effect of education on permanent income increase in size as the level of education graduates from primary certificates to post-secondary diplomas. This finding confirms the apparent benefits of education in improving household welfare. The employment status of the household head had the expected on household income, specifically that, compared to waged and predictable employment, participating in occupations in agriculture and small-scale businesses caused a reduction in household income, with the reduction bigger for those employed in agriculture. Lastly, the effect of rainfall was found to be mixed depending on the agro-ecological location. For the general model and for the ASALs households, the coefficient of annual average rainfall was positive but negative when squared to indicate that the positive effect of the amount of rainfall had a tipping point from which more rainfall caused damages that result to income reduction. However, for the households in high potential zones where rainfall is in plenty, the coefficient was negative to indicate the already underlying condition of adequate rainfall and that an increase causes a reduction in household income. Instructively, the high potential zones experience disproportionately more rain-related calamities such as floods, landslides and malaria.

The approach of decomposing household income into permanent and transitory components failed to yield distinct estimates of permanent and transitory incomes when applied to this study's data. This can be attributed to a possible measurement error in the variables such as household income. First, the reported income is most likely underreported, given that 88 percent of the respondents reported incomes lower than total consumption with variances reaching up to KES. 1,062,661. Secondly, the reported income is an aggregation of household receipts from disparate sources and at different times as dictated by seasons, creating a possibility of incorrect measurement. In addition, using this approach, especially the one followed by Cameron and Worswick (2001) in which the intercept of the fitted income equation $\left(\hat{\alpha}_{0}\right)$ is used to calculate fitted values of permanent and unexplained incomes $\left(\hat{Y}_{i}^{P}\right.$ and $\left.\hat{\epsilon}_{i}\right)$ brought about collinearity in the consumption estimation model. 


\subsection{Effect of Transitory Income Shocks on Household Consumption Expenditures}

These challenges and estimation pitfalls of household income decomposition necessitated the use of a different approach in which the household income is not decomposed into the various components. To capture the effect of transitory income shocks in the model, we introduce the crop loss dummy as shown in equation six.

$$
E X P_{i}=\eta_{0}+\eta_{1} Y_{i}+\eta_{2} \text { Croploss }_{i}+\eta_{3} \text { Croploss } \times Y_{i}+\eta_{4} X_{i}+\mu_{i}
$$

Where $Y_{i}$ is the household reported income, Croploss $s_{i}$ is a dummy representing one if the household reported crop loss and zero otherwise, Croploss $\times Y$ is the interaction term of income and the dummy of transitory income shock (crop loss). In this case, income counteracts the reducing effect of the shock on household consumption expenditures. Similar to equation five, $X_{i}$ represents other household controls that are known to influence household consumption expenditures and include the number of household members in different age categories. $\eta_{0}, \eta_{1}, \eta_{2}, \eta_{3}$ and $\eta_{4}$ denote the model coefficients and $\mu_{i}$ is the error term capturing the observed determinants of consumption and is assumed to have condition mean zero. The household consumption expenditures is represented by $E X P_{i}$, and estimations are done for total consumption, non-food, food, health and education expenditures for the countrywide sample size and also disaggregated for the two agro-ecological zones. Results of these estimations are provided in tables four, five and six.

For the countrywide sample size, the coefficient of the household income variable was positive and statistically significant for all the expenditure categories. Households that experienced crop loss had a statistically significant reduction in the aggregate, food and non-food expenditures compared to the ones that did not experience crop loss. These results indicate there is a negative association between transitory income shocks and the volatility in the general household consumption. A similar association is also observed when consumption is disaggregated into food and non-food expenditures, but the results are not significant in the coefficients of health and education. This could be explained by the fact that in most of rural areas of Kenya, health and education infrastructure are homogenous and less disaggregated on cost. In addition, households largely utilize the publicly-provided education and health services, and therefore household expenditures on these services are fairly minimal and generally insulated from transitory income shocks. This however excludes catastrophic health expenditures, but it was not uncovered in this study.

The coefficient of the interaction between crop loss and household income came out as not significant at 10 percent for all the expenditure categories. This means that the expected counteractive effect of income on crop loss is missing. Indeed, there is a negative relation between incidence of transitory income shocks (crop loss) and income, indicating that households with low incomes (and those whose the household head is employed in the agricultural sector, compared to those in waged employment) are those most likely to report crop loss and thus cannot use income to shore up consumption. This finding also indicate that incomes are too negligible to have any smoothing role on consumption fluctuations.

Table 4: Effect of Shocks on Household Consumption Expenditures Categories - Whole country

\begin{tabular}{|c|c|c|c|c|c|}
\hline \multirow[b]{2}{*}{ Variable } & \multicolumn{5}{|c|}{ Expenditure Categories } \\
\hline & Aggregate & Non-Food & Food & Health & Education \\
\hline Household & $.40271 * * *$ & $.25171 * * *$ & $.15100 * * *$ & $.00489 * *$ & $.05394 * * *$ \\
\hline Income & $(.02725)$ & $(.01888)$ & $(.01543)$ & $(.00190)$ & $(.01069)$ \\
\hline \multirow[t]{2}{*}{ Crop Loss } & $-9418.57 * * *$ & $-4711.31 * * *$ & $-4707.26 * * *$ & -122.59 & -514.74 \\
\hline & (1980.08) & $(1214.23)$ & $(1286.91)$ & $(76.87)$ & $(538.71)$ \\
\hline Crop Loss $X$ & -.00313 & -.00771 & .00458 & -.00088 & -.00194 \\
\hline Income & $(.04626)$ & $(.03283)$ & $(.02399)$ & $(.00219)$ & $(.01818)$ \\
\hline \multicolumn{6}{|c|}{ Number of household members between ages: } \\
\hline 0 to 5 & $\begin{array}{l}-1234.40 \\
(843.69)\end{array}$ & $\begin{array}{l}-2705.06^{* * *} \\
(523.22)\end{array}$ & $\begin{array}{l}1470.65 * * * \\
(547.67)\end{array}$ & $\begin{array}{l}-5.36 \\
(31.52)\end{array}$ & $\begin{array}{l}-2121.22 * * * \\
(231.56)\end{array}$ \\
\hline \multirow[t]{2}{*}{6 to 11} & $2843.99 * * *$ & $-880.08 *$ & $3724.07 * * *$ & -15.63 & $-616.47 * *$ \\
\hline & $(790.60)$ & $(519.08)$ & $(483.16)$ & $(25.45)$ & $(268.37)$ \\
\hline \multirow[t]{2}{*}{12 to 17} & $7509.91 * * *$ & $3181.11 * * *$ & $4328.8^{* * *}$ & -27.21 & $2606.47 * * *$ \\
\hline & $(841.91)$ & $(533.99)$ & $(543.72)$ & $(32.17)$ & $(335.27)$ \\
\hline \multirow[t]{2}{*}{18 to 64} & $13194.18^{* * *}$ & $7317.17 * * *$ & $5877.01 * * *$ & $108.79 * * *$ & $4124.59 * * *$ \\
\hline & $(856.86)$ & $(648.98)$ & $(440.95)$ & $(28.62)$ & $(386.31)$ \\
\hline \multirow[t]{2}{*}{ Over 64} & $4481.65 * *$ & -441.69 & $4923.33 * * *$ & $127.07 *$ & -162.23 \\
\hline & (1764.08) & $(1161.20)$ & $(1053.26)$ & $(76.17)$ & $(358.48)$ \\
\hline \multirow[t]{2}{*}{ Intercept } & $39567.64 * * *$ & $7975.17 * * *$ & $31592.47 * * *$ & $491.27 * * *$ & $-4754.42 * * *$ \\
\hline & $(2220.0)$ & $(1512.37)$ & $(1368.14)$ & $(82.45)$ & $(956.39)$ \\
\hline$N$ & 5,828 & 5,828 & 5,828 & 5,828 & 5,828 \\
\hline $\mathrm{R}^{2}$ & 0.2098 & 0.1696 & 0.1350 & 0.0127 & 0.1601 \\
\hline F-Values & $124.74 * * *$ & $68.63 * * *$ & $89.10 * * *$ & $7.36 * * *$ & $26.39 * * *$ \\
\hline
\end{tabular}

Robust standard errors are in brackets. $* * *, * *, *$ : significant at $1 \%, 5 \%$ and $10 \%$ respectively 
We disaggregated the national sample into two geographic zones, high and medium potential zones and ASALs, based on the agro-climatic conditions. High and medium zones have higher potential for agricultural production and constitute 17 to 20 percent of Kenya's land mass while the ASALs, covering up to 80 percent of land mass receive depressed rainfall which negatively impact on crop production (Republic of Kenya, 2012). The incidence and effects of crop loss shocks therefore differ according to the agro-ecological location of a household. The analytical approach of disaggregating households according to their climatic locations has also been applied for Kenyan data by Wineman, et al., (2016). The results for the estimation of effects of transitory income shocks on household consumption for high and medium potential zones is provided in table five.

Table 5: Effect of Shocks on Household Consumption Expenditures Categories - High and Medium Potential Zones

\begin{tabular}{|c|c|c|c|c|c|}
\hline \multirow[b]{2}{*}{ Variable } & \multicolumn{5}{|c|}{ Expenditure Categories } \\
\hline & Aggregate & Non-Food & Food & Health & Education \\
\hline Household & $.39282 * * *$ & $.25378 * * *$ & $.13903 * * *$ & $.00532 * *$ & $.05124 * * *$ \\
\hline Income & $(.03008)$ & $(.02120)$ & $(.01707)$ & $(.00227)$ & $(.01210)$ \\
\hline \multirow[t]{2}{*}{ Crop Loss } & -2692.39 & -2515.38 & -177.01 & 7.90 & -163.47 \\
\hline & $(2592.83)$ & $(1702.79)$ & $(1624.99)$ & $(102.85)$ & $(753.22)$ \\
\hline Crop Loss $\times$ & .03254 & .02537 & .00716 & .00030 & .00928 \\
\hline Income & $(.05948)$ & $(.04493)$ & $(.02853)$ & $(.00282)$ & $(.02481)$ \\
\hline \multicolumn{6}{|c|}{ Number of household members between ages: } \\
\hline \multirow[t]{2}{*}{0 to 5} & -715.95 & $-2545.64 * * *$ & $1829.69 * *$ & -1.44 & $-2175.89 * * *$ \\
\hline & $(1044.62)$ & $(669.77)$ & $(685.42)$ & $(42.25)$ & $(294.19)$ \\
\hline \multirow[t]{2}{*}{6 to 11} & $3693.49 * * *$ & -507.40 & $4200.89 * * *$ & -11.34 & $-664.78 *$ \\
\hline & $(1015.20)$ & $(696.16)$ & $(608.35)$ & $(34.31)$ & $(363.14)$ \\
\hline \multirow[t]{2}{*}{12 to 17} & $9477.37 * * *$ & $4383.42 * * *$ & $5093.94 * * *$ & -21.32 & $3287.08 * * *$ \\
\hline & $(1049.16)$ & $(696.093)$ & $(676.68)$ & $(43.52)$ & $(458.65)$ \\
\hline \multirow[t]{2}{*}{18 to 64} & $15653.13 * * *$ & $8642.31 * * *$ & $7010.83 * * *$ & $151.86^{* * *}$ & $4859.58 * * *$ \\
\hline & $(1079.73)$ & $(859.83)$ & $(543.81)$ & $(39.16)$ & $(509.56)$ \\
\hline \multirow[t]{2}{*}{ Over 64} & $7421.15 * * *$ & 1244.07 & $6177.08 * * *$ & $257.23 * *$ & 169.72 \\
\hline & $(2251.66)$ & $(1551.21)$ & $(1311.72)$ & (106.94) & $(437.58)$ \\
\hline \multirow[t]{2}{*}{ Intercept } & $33786.33 * * *$ & $4579.72 * *$ & $29206.61 * * *$ & $403.00 * * *$ & $-6455.53 * * *$ \\
\hline & $(2664.60)$ & (1966.8) & $(1625.42)$ & $(105.52)$ & $(1236.65)$ \\
\hline$N$ & 4,203 & 4,203 & 4,203 & 4,203 & 4,203 \\
\hline $\mathrm{R}^{2}$ & 0.2312 & 0.1799 & 0.1487 & 0.0148 & 0.1803 \\
\hline F-Values & $100.79 * * *$ & $51.10 * * *$ & $71.50 * * *$ & $5.66 * * *$ & $20.12 * * *$ \\
\hline
\end{tabular}

Robust standard errors are in brackets. $* * *, * *, *$ : significant at $1 \%, 5 \%$ and $10 \%$ respectively

Similar to what was found with the national sample size, the coefficient for income is positive and statistically significant for all categories of household consumption expenditures. On the other hand, the coefficients of the dummy of transitory income shocks and interaction of this dummy with income are not statistically significant at 10 percent level. In addition, coefficients of control variables vary differently across different consumption expenditure categories. Contrary to the findings of the countrywide sample size, these findings indicate that in the high and medium potential zones, the consumption expenditures are not associated with whether a household experienced crop loss-related shocks which include droughts, floods, crop diseases and pests. These findings are consistent with other empirical studies in Kenya that found that depressed precipitation induced shocks in the ASALs while too much rainfall had negative effect on crop production in the highlands (Christiaensen and Subbarao, 2004; Wineman, et al., 2016). These results could be due to various reasons. First, only 32 percent of the households reported being affected by crop loss related shocks in the high and medium agro-ecological zones compared to the countrywide average of 42 percent. These zones receive adequate rainfall and are mostly found in high-elevated and drained grounds thus minimizing incidences of droughts and floods. In addition, because they are the bread baskets of the country, they get adequate agricultural extension support and infrastructure to mitigate against crop pests and diseases. Thus, the crop loss-related shocks are mostly idiosyncratic in nature, emanating from possibly non-adherence to best crop production practices such as delayed planting, non-use of fertilizer, nonadherence of spraying regimens among others. Therefore, because these reported crop loss shocks are likely to be household specific, the affected families could turn to neighbours or rely on other enterprises to smooth consumption.

Finally, a similar analysis was done for households in the ASALs and the results are presented in table six. While no serious multicollinearity was found between household income on one side and the other explanatory variables on the other in the countrywide and highlands sample sizes, the variance inflation factor (VIF) values for the interaction term of household income with the dummy of transitory income shocks was found to approach the critical four for the ASALs sample size and thus the interaction variable was omitted from the equation. 
The results of the coefficient of income variable are consistent with similar estimations using the countrywide and the highlands sample sizes, that is, positive and statistically significant for all expenditure categories. The results for the coefficient of crop loss (measuring transitory income shocks) were mixed. The coefficients of the aggregate and food expenditures were as expected, negative and statistically significant at five percent level. Households in the ASALs that reported transitory income shocks had a KES. 5,795 and KES. 3,586 reduction in aggregate and food expenditures respectively compared to those not reporting the shocks. Christiaensen and Subbarao (2004) also found that weather and climatic related shocks were likely to cause welfare reduction of those in rain-depressed areas than those in the highlands. These findings indicate that there is pronounced vulnerability of ASALs households to transitory income shocks compared to households in rich agricultural zones. In addition, while households in the latter zones are able to smooth food consumption from shocks, those in the former reduce on food consumption when transitory incomes drop, which is a response mechanism with potential adverse effects on household welfare, specifically development of long-term human capital.

Regarding the non-significance of coefficients of health and education, which are essential expenditures for the human capital development, it could indicate that households in the ASALs have mechanisms to insulate health and education spending from transitory income shocks. however this proposition is not supported by findings of a demographic and health survey carried out in the country in 2014 that showed counties in the ASALs having lower values of key health indicators such as maternal care, vaccination and child health as well as treatment-seeking for common diseases such as fever, malaria and diarrhea (Republic of Kenya, 2014). The most plausible explanation of none-significance of these coefficients is that households in the ASALs spent less on health and education compared to those in highlands. For instance, this data shows that 42 percent of ASALs households reported zero expenditure on health compared to 27 percent of households in highlands. Similarly, 28 percent of the latter reported zero spending in education compared to 24 percent in the latter category. In addition, the data revealed that households reporting zero expenditure in education in the ASALs, 67 percent were those who reported being affected by shocks leading to crop loss.

Table 6: Effect of Shocks on Household Consumption Expenditures Categories - Arid and Semi-Arid Zones

\begin{tabular}{|c|c|c|c|c|c|}
\hline \multirow[b]{2}{*}{ Variable } & \multicolumn{5}{|c|}{ Expenditure Categories } \\
\hline & Aggregate & Non-Food & Food & Health & Education \\
\hline Household & $.38553^{* * *}$ & $.21010 * * *$ & $.17543 * * *$ & $.00197 * * *$ & $.05017 * * *$ \\
\hline Income & $(.04017)$ & $(.02377)$ & $(.02433)$ & $(.00065)$ & $(.01035)$ \\
\hline Crop Loss & $-5794.87 * *$ & -2209.05 & $-3585.82 * *$ & -98.30 & 569.85 \\
\hline & $(2496.58)$ & $(1413.17)$ & $(1666.33)$ & $(64.10)$ & $(680.12)$ \\
\hline \multicolumn{6}{|c|}{ Number of household members between ages: } \\
\hline 0 to 5 & $\begin{array}{l}-378.46 \\
(1259.50)\end{array}$ & $\begin{array}{l}-2075.97 * * * \\
(715.85)\end{array}$ & $\begin{array}{l}1697.51^{* *} \\
(834.05)\end{array}$ & $\begin{array}{l}42.65 \\
(31.71)\end{array}$ & $\begin{array}{l}-1784.04 * * * \\
(336.38)\end{array}$ \\
\hline 6 to 11 & $\begin{array}{l}2978.13 * * * \\
(1029.34)\end{array}$ & $\begin{array}{l}-701.35 \\
(530.05)\end{array}$ & $\begin{array}{l}3679.48 * * * \\
(743.81)\end{array}$ & $\begin{array}{l}15.82 \\
(30.36)\end{array}$ & $\begin{array}{l}-218.99 \\
(259.13)\end{array}$ \\
\hline 12 to 17 & $\begin{array}{l}4233.76^{* * *} \\
(1265.81)\end{array}$ & $\begin{array}{l}1078.68 \\
(680.90)\end{array}$ & $\begin{array}{l}3155.08^{* * * *} \\
(858.18)\end{array}$ & $\begin{array}{l}-9.24 \\
(26.05)\end{array}$ & $\begin{array}{l}1208.56^{* * *} \\
(314.02)\end{array}$ \\
\hline 18 to 64 & $\begin{array}{l}7781.05^{* * * *} \\
(1078.36)\end{array}$ & $\begin{array}{l}4361.30 * * * \\
(672.37)\end{array}$ & $\begin{array}{l}3419.75^{* * * *} \\
(632.42)\end{array}$ & $\begin{array}{l}21.68 \\
(17.17)\end{array}$ & $\begin{array}{l}2374.46^{* * * *} \\
(394.43)\end{array}$ \\
\hline Over 64 & $\begin{array}{l}3678.85 \\
(2395.38)\end{array}$ & $\begin{array}{l}-1138.06 \\
(1328.67)\end{array}$ & $\begin{array}{l}4816.91 * * * \\
(1643.74)\end{array}$ & $\begin{array}{l}-66.77 \\
(45.33)\end{array}$ & $\begin{array}{l}154.64 \\
(591.93)\end{array}$ \\
\hline Intercept & $\begin{array}{l}38384.65 * * * \\
(3497.69)\end{array}$ & $\begin{array}{l}9061.56 \\
(1908.76) \\
\end{array}$ & $\begin{array}{l}29323.09 * * * \\
(2381.39)\end{array}$ & $\begin{array}{l}385.49 \\
(77.89)\end{array}$ & $\begin{array}{l}-2431.09 * * * \\
(866.20)\end{array}$ \\
\hline$N$ & 1,625 & 1,625 & 1,625 & 1,625 & 1,625 \\
\hline $\mathrm{R}^{2}$ & 0.1958 & 0.1663 & 0.1381 & 0.0113 & 0.1276 \\
\hline F-Values & $39.09 * * *$ & $24.37 * * *$ & $30.63 * * *$ & $5.42 * * *$ & $14.77 * * *$ \\
\hline
\end{tabular}

Robust standard errors are in brackets. $* * *, * *, *$ : significant at $1 \%, 5 \%$ and $10 \%$ respectively

\section{Conclusions and Policy Implications}

Vulnerability of livelihoods to various shocks is a serious threat to welfare among rural households, especially in low-income countries. This study investigated how food, health and education expenditures are influenced by transitory income shocks among rural households in Kenya. A decomposition of household income into permanent and transitory components was not supported using this data so the estimation slightly modified to include the dummy variable on transitory income shocks (measured as crop loss) in the consumption estimation equation. In addition to assessing the consumption response for the countrywide sample size, a disaggregation based on agroecological zones was also applied to factor in differences in rural households' exposure to and incidences of transitory income shocks. The necessary estimation robustness checks were applied to ensure that results were valid and could thus be interpreted. 
For the countrywide sample size, we find that consumption is positively associated with income for the aggregate expenditures as well as specific categories of food, non-food, health and education. Specifically, we establish that households that experienced shocks leading to crop loss had a substantial reduction in their mean annual aggregate consumption spending as well as reductions in expenditures in food and non-food. There are however clear differences when the agro-ecological zoning is considered. Transitory income shocks appear not to have any reducing effect on the spending of households in high and medium potential zones. On the other hand, shock-prone households in ASALs had distinctive and statistically significant dip in aggregate and food spending compared to their counterparts not affected by shocks. The results are generally consistent with the incomeconsumption literature for households in low-resource environments.

The results further show that rural households are heavily dependent on public education and health facilities. This partly explains why expenditures on health and education appeared insulated from transitory income shocks. Public policy should therefore be about promoting quality and coverage of these essential services and promoting awareness among the local people to seek medical attention in health facilities instead of resorting to selfmedication and questionable traditional healers. To sum up, there is a clear trend that household consumption vulnerability and exposure has a poverty dimension and therefore to effectively address this, the existing government poverty alleviation programmes need to focus clearly on drivers of impoverishment such as transitory income shocks.

Overall, the findings of the study illuminate the vulnerability of households' food consumption to transitory income shocks, especially in the ASALs. The mean household consumption of food in ASALs is half that of highmedium potential zones (KES. 34,084 compared to KES 63,075), and also most prone to transitory income shocks when compared to households in the highlands. It is also below the national average of KES. 60,149 indicating the possibility that households in the ASALs could be getting less than the recommended calorie intake. This is the basis for governments to improve the shock-resilience capacity of households in ASALs through, for instance, climate-smart farming techniques, tailored extension services and improvement of basic infrastructure to spur offfarm employment opportunities.

\section{Acknowledgements}

Philip K Musyoka acknowledges the financial support from the African Economic Research Consortium (AERC) towards this study. The findings, opinions and recommendations are those of the authors, however, and do not necessarily reflect the views of the Consortium, its individual members or the AERC Secretariat. The authors appreciate helpful comments received on earlier drafts of this paper. Any errors are the responsibility of the authors.

\section{References}

Alderman, H., \& Haque, T. (2006). Countercyclical safety nets for the poor and vulnerable. Food Policy, 31(4), 372-383.

Asiimwe, J. B., \& Mpuga, P. (2007). Implications of rainfall shocks for household income and consumption in Uganda (No. RP 168 Key words: Farm households, income, consumption expenditure, shocks, rainfall variability). African Economic Research Consortium.

Baez, J. E., Kronick, D., \& Mason, A. D. (2013). Rural households in a changing climate. The World Bank.

Baez, J. E., Lucchetti, L., Genoni, M. E., \& Salazar, M. (2017). Gone with the storm: rainfall shocks and household wellbeing in Guatemala. The Journal of Development Studies, 53(8), 1253-1271.

Berloffa, G., \& Modena, F. (2013). Income shocks, coping strategies, and consumption smoothing: An application to Indonesian data. Journal of Asian Economics, 24, 158-171.

Blundell, R., Pistaferri, L., \& Preston, I. (2008). Consumption inequality and partial insurance. American Economic Review, 98(5), 1887-1921.

Cameron, L. A., \& Worswick, C. (2001). Education expenditure responses to crop loss in Indonesia: A gender bias. Economic development and cultural change, 49(2), 351-363.

Carroll, C. D. (2001). A theory of the consumption function, with and without liquidity constraints. Journal of Economic perspectives, 15(3), 23-45.

Christiaensen, L. J., \& Subbarao, K. (2005). Towards an understanding of household vulnerability in rural Kenya. Journal of African Economies, 14(4), 520-558.

Cochrane, J. H. (1991). A simple test of consumption insurance. Journal of political economy, 99(5), 957-976.

Cochrane, J. H. (1991). A simple test of consumption insurance. Journal of political economy, 957-976.

Collins, D., Cojocaru, L., \& Zollman, J. (2015). Getting an Education in Rural Kenya: Findings based on the Kenya Financial Diaries. Jacobs Foundation, Zurich.

Deaton, A. (1990). On Risk, Insurance and Intra-Village Consumption Smoothing. Preliminary Draft, Research Program in Development Studies. Princeton University. Available on https://www.princeton.edu/ deaton/downloads

Deaton, A. (2003). Household surveys, consumption, and the measurement of poverty. Economic Systems 
Research, 15(2), 135-159.

Dercon, S. (2002). Income risk, coping strategies, and safety nets. The World Bank Research Observer, 17(2), 141-166.

Fafchamps, M., \& Lund, S. (2003). Risk-sharing networks in rural Philippines. Journal of development Economics, 71(2), 261-287.

Fafchamps, M., Udry, C., \& Czukas, K. (1998). Drought and saving in West Africa: are livestock a buffer stock?. Journal of Development economics, 55(2), 273-305.

FAO (2017). http://www.fao.org/americas/noticias/ver/en/c/892863/

Friedman, M. (1957). "Introduction to" A Theory of the Consumption Function"." In A theory of the consumption function, pp. 1-6. Princeton University Press, 1957. Retrieved from www.nber.org

Grimard, F. (1997). Household consumption smoothing through ethnic ties: evidence from Cote d'Ivoire. Journal of development Economics, 53(2), 391-422.

Günther, I., \& Harttgen, K. (2009). Estimating households vulnerability to idiosyncratic and covariate shocks: a novel method applied in Madagascar. World Development, 37(7), 1222-1234.

Hoddinott, J. (2006). Shocks and their consequences across and within households in rural Zimbabwe. The Journal of Development Studies, 42(2), 301-321.

Jacoby, H. G., \& Skoufias, E. (1997). Risk, financial markets, and human capital in a developing country. The Review of Economic Studies, 64(3), 311-335.

Jappelli, T., \& Pistaferri, L. (2010). The Consumption Response to Income Changes. Annual Review of Economics, 2, 479-506.

Kazianga, H., \& Udry, C. (2006). Consumption smoothing? Livestock, insurance and drought in rural Burkina Faso. Journal of Development economics, 79(2), 413-446.

Kim, J., \& Prskawetz, A. (2010). External shocks, household consumption and fertility in Indonesia. Population research and policy review, 29(4), 503-526.

Kim, J., Engelhardt-Wölfler, H., Fürnkranz-Prskawetz, A., \& Aassve, A. (2009). Does fertility decrease household consumption?: An analysis of poverty dynamics and fertility in Indonesia. Demographic Research, 20, 623656.

Kochar, A. (1999). Smoothing consumption by smoothing income: hours-of-work responses to idiosyncratic agricultural shocks in rural India. Review of Economics and Statistics, 81(1), 50-61.

Krueger, D., \& Perri, F. (2006). Does income inequality lead to consumption inequality? Evidence and theory. The Review of Economic Studies, 73(1), 163-193.

Kumar, P., \& Singh, S. K. (2012). Consumption Smoothing and Insurance against the Income Risks: A Case of India. Indian Economic Review, 265-283.

Mace, B. J. (1991). Full insurance in the presence of aggregate uncertainty. Journal of Political Economy, 99(5), 928-956.

Maxwell, D., Webb, P., Coates, J., \& Wirth, J. (2010). Fit for purpose? Rethinking food security responses in protracted humanitarian crises. Food policy, 35(2), 91-97.

McCarthy, J. (1995). Imperfect insurance and differing propensities to consume across households. Journal of Monetary Economics, 36(2), 301-327.

McCarthy, N., Brubaker, J., \& De La Fuente, A. (2016). Vulnerability to Poverty in rural Malawi. The World Bank. Available online

on http://documents.worldbank.org/curated/en/939091469543760391/pdf/WPS7769.pdf

McPeak, J. (2004). Contrasting income shocks with asset shocks: livestock sales in northern Kenya. Oxford Economic Papers, 56(2), 263-284.

Meghir, C. (2004). A retrospective on Friedman's theory of permanent income. The Economic Journal, 114(496), F293-F306.

Modigliani, F., \& Brumberg, R. (1954). Utility analysis and the consumption function: An interpretation of crosssection data. Franco Modigliani, 1 .

Morduch, J. (1999). Between the state and the market: Can informal insurance patch the safety net?. The World Bank Research Observer, 14(2), 187-207.

Newhouse, D. (2001). Do Negative Income Shocks Last Longer, and Do They Hurt the Poor More? Evidence from Rural Indonesia. mimeo, Cornell University.

Paxson, C. H. (1992). Using weather variability to estimate the response of savings to transitory income in Thailand. The American Economic Review, 15-33.

Republic of Kenya (2012). State of the Environment 2011. Government Printer, Nairobi, Kenya.

Republic of Kenya (2014). Demographic and Health Survey: Key Indicators 2014. Government Printer, Nairobi, Kenya.

Republic of Kenya (2017). 2009 Population and Housing Census. Available online at https://www.knbs.or.ke/publications/?wpdmc=detailed-census-results 
Republic of Kenya (2018). Kenya Economic Survey. Government Printer, Nairobi, Kenya.

Republic of Kenya (various years). Kenya Economic Survey. Government Printer, Nairobi, Kenya.

Rosenzweig, M. R. (2001). Savings behaviour in low-income countries. Oxford Review of Economic Policy, 17(1), 40-54.

Rosenzweig, M. R., \& Wolpin, K. I. (1993). Credit market constraints, consumption smoothing, and the accumulation of durable production assets in low-income countries: Investments in bullocks in India. Journal of political economy, 101(2), 223-244.

Salami, A., Kamara, A. B., \& Brixiova, Z. (2010). Smallholder agriculture in East Africa: Trends, constraints and opportunities. Tunis: African Development Bank.

Sirisankanan, A. (2015). Risk, uncertainty and consumption-smoothing mechanisms: Evidence from Thai household socio-economic panel data. Journal of Southeast Asian Economies, 163-179.

Srivastava, A., \& Mohanty, S. K. (2010). Economic proxies, household consumption and Health estimates. Economic and Political Weekly, 55-63.

Subbarao, K., Bonnerjee, A., Braithwaite, J., Carvalho, S., Ezemenari, K., Graham, C., \& Thompson, A. (1997). Safety net programs and poverty reduction: Lessons from cross-country experience. The World Bank.

Townsend, R. M. (1994). Risk and insurance in village India. ECONOMETRICA-EVANSTON ILL-, 62, 539-539. Available on http://econ.tu.ac.th/archan/supachai/EC625/Reading\%20List/Townsend\%20(1994).pdf

Udry, C. (1990). Credit markets in Northern Nigeria: Credit as insurance in a rural economy. The World Bank Economic Review, 4(3), 251-269.

Webb, P., Stordalen, G. A., Singh, S., Wijesinha-Bettoni, R., Shetty, P., \& Lartey, A. (2018). Hunger and malnutrition in the 21st century. bmj, 361, k2238. Available on https://www.bmj.com/content/361/bmj.k2238.full

Weil, P. (1993). Precautionary savings and the permanent income hypothesis. The Review of Economic Studies, 60(2), 367-383.

Wineman, A., Mason, N. M., Ochieng, J., \& Kirimi, L. (2016). Let it rain: Weather extremes and household welfare in rural Kenya (No. 680-2016-46738). Available http://tegemeo.org/images/downloads/publications/working_papers/WP57_2016.pdf

Wolpin, K. I. (1982). A new test of the permanent income hypothesis: the impact of weather on the income and consumption of farm households in India. International Economic Review, 583-594.

Zeldes, S. P. (1989). Consumption and liquidity constraints: an empirical investigation. Journal of political economy, 97(2), 305-346.

Zimmerman, F. J., \& Carter, M. R. (2003). Asset smoothing, consumption smoothing and the reproduction of inequality under risk and subsistence constraints. Journal of Development Economics, 71(2), 233-260. 


\section{Appendices}

Table 7: Earnings from crop sales per county

\begin{tabular}{|c|c|}
\hline County & Mean Earning from Crop Sales (KES) \\
\hline Bomet & 20,186 \\
\hline Meru & 16,237 \\
\hline Uasin Gishu & 15,935 \\
\hline Narok & 15,549 \\
\hline Embu & 13,359 \\
\hline Kirinyaga & 13,170 \\
\hline Muranga & 12,997 \\
\hline Taita Taveta & 11,736 \\
\hline Nakuru & 11,686 \\
\hline Nyeri & 11,359 \\
\hline Migori & 10,482 \\
\hline Nandi & 10,281 \\
\hline Nyandarua & 10,072 \\
\hline Trans Nzoia & 9,550 \\
\hline Elgeyo Marakwet & 8,298 \\
\hline West Pokot & 8,169 \\
\hline Kakamega & 6,989 \\
\hline Tharaka Nithi & 6,970 \\
\hline Bungoma & 6,782 \\
\hline Kericho & 6,715 \\
\hline Nyamira & 6,527 \\
\hline Kisii & 6,390 \\
\hline Kiambu & 4,438 \\
\hline Machakos & 3,980 \\
\hline Baringo & 3,473 \\
\hline Kitui & 3,103 \\
\hline Homa Bay & 2,651 \\
\hline Kajiado & 2,411 \\
\hline Lamu & 2,370 \\
\hline Kilifi & 2,105 \\
\hline Laikipia & 2,078 \\
\hline Makueni & 1,443 \\
\hline Kwale & 1,335 \\
\hline Tana River & 1,270 \\
\hline Busia & 1,006 \\
\hline Vihiga & 895 \\
\hline Siaya & 645 \\
\hline Isiolo & 495 \\
\hline Kisumu & 352 \\
\hline Mandera & 194 \\
\hline Marsabit & 65 \\
\hline Turkana & 25 \\
\hline Garissa & 11 \\
\hline Samburu & 2 \\
\hline Wajir & - \\
\hline
\end{tabular}


Table 8: Earnings from Livestock sales per county

\begin{tabular}{|c|c|}
\hline County & Mean Earning from Livestock Sales (KES) \\
\hline Kajiado & 27,218 \\
\hline Narok & 26,070 \\
\hline Wajir & 12,483 \\
\hline Kiambu & 11,155 \\
\hline West Pokot & 10,939 \\
\hline Baringo & 9,863 \\
\hline Garissa & 9,831 \\
\hline Isiolo & 9,528 \\
\hline Marsabit & 7,133 \\
\hline Kitui & 6,725 \\
\hline Mandera & 6,455 \\
\hline Nyandarua & 6,230 \\
\hline Samburu & 6,148 \\
\hline Makueni & 5,756 \\
\hline Tharaka Nithi & 5,240 \\
\hline Bomet & 5,220 \\
\hline Lamu & 5,185 \\
\hline Machakos & 5,169 \\
\hline Bungoma & 5,050 \\
\hline Elgeyo Marakwet & 4,964 \\
\hline Meru & 4,928 \\
\hline Nakuru & 4,882 \\
\hline Laikipia & 4,746 \\
\hline Migori & 4,321 \\
\hline Nandi & 4,238 \\
\hline Tana River & 3,986 \\
\hline Uasin Gishu & 3,629 \\
\hline Muranga & 3,467 \\
\hline Kericho & 3,065 \\
\hline Kakamega & 2,901 \\
\hline Kisumu & 2,831 \\
\hline Nyamira & 2,827 \\
\hline Kirinyaga & 2,803 \\
\hline Nyeri & 2,791 \\
\hline Kisii & 2,709 \\
\hline Homa Bay & 2,697 \\
\hline Embu & 2,665 \\
\hline Trans Nzoia & 2,334 \\
\hline Taita Taveta & 2,244 \\
\hline Vihiga & 2,212 \\
\hline Kwale & 1,688 \\
\hline Siaya & 1,641 \\
\hline Busia & 1,589 \\
\hline Kilifi & 1,068 \\
\hline Turkana & 787 \\
\hline
\end{tabular}

